\title{
The grander challenge of pediatric oncology: disparities in access to care
}

\author{
Joseph Lubega ${ }^{1}$ \\ ${ }^{1}$ Baylor College of Medicine
}

September 28, 2021

The grander challenge of pediatric oncology: disparities in access to care

Joseph Lubega, M.D., M.S., C.P.E.

Baylor College of Medicine

6701 Fannin St., Ste. 1510 Houston, TX 77030

lubega@bcm.edu

Phone: +1 8328224242

Fax: +1 8328251453

Word count: 968

Short running title: Disparities in access to pediatric cancer care

Keywords: pediatric cancer, disparities, global, minorities

The excellent survival of children with cancer in the United States (US) is a grand achievement that has been accomplished mainly through five decades of translating biomedical discoveries to the bedside. However, it obscures the significantly inferior survival of racial-ethnic minorities in the US ${ }^{1,2}$, and highlights the unconscionably abysmal survival of children with cancer globally ${ }^{3}$. Intrinsic differences in epidemiology of prognostically relevant tumor and host biological factors contribute to these survival disparities. However, as demonstrated by the fact that the widest survival disparities occur among children with the most curable cancers and risk-groups ${ }^{2,4}$, the primary driver of inferior survival among minorities and children globally islack of access to effective pediatric cancer care. Discovery of efficacious therapies was/is the grand challenge to pediatric oncology; ensuring access to effective care for all children in the US and globally is the grander challenge of pediatric oncology.

Access to health services is a complex construct that includes ${ }^{5}$ : (1) availability of the services to a specific population, (2) adequate supply of the services to the population, (3) ability to utilize the health services, which includes requisite financial (e.g., medical insurance coverage) and social (e.g., flexibility of work schedule to attend medical appointments) resources, and (4) suitability of the services to the socio-cultural context of all demographic groups in the population. For the majority of the world's children that develop cancer $(\sim 80 \%)$ and live in low/middle income countries, infrastructure and expertise for evidence-based pediatric oncology services are simply unavailable or are extremely scanty. On the other hand, racial-ethnic minorities in the US also suffer from lack of access to adequate pediatric oncology care despite the apparent abundance of services - suggesting barriers to utilization and/or suitability of services.

In this issue of Pediatric Blood $\mathscr{G}$ Cancer, Zheng D.J. et al present an evaluation of access to a psychiatry service that is integrated into a children's cancer center - the Dana-Farber/Boston Children's Cancer and 
Blood Disorders Center (DF/BCH) from 2013 to 2017. The authors examined the relationship between utilization of this psychiatry service and patients' socio-demographic characteristics. Among a sample of 394 children with cancer that were evaluated, racial/ethnic minorities had $52 \%$ lower odds of using the psychiatry service. Household material hardship and household income, two indicators of financial deprivation that may be considered the most obvious determinants of service utilization, did not influence utilization of this psychiatry service. For children who utilized the psychiatry service, $88 \%$ were diagnosed with a psychiatric disorder, $76 \%$ were given a pharmacological therapy and $62 \%$ were given a behavioral intervention for their diagnosis. The high occurrence of a specific diagnosis and therapeutic interventions for the children that used the psychiatry services suggest that this is a highly valuable service for children that are referred.

Zheng D.J. et al's findings demonstrate that availability of services does not equate to access, and that it is often difficult to pin-point the underlying reasons. Although racial-ethnic minorities in the US are associated with financial deprivation, financial indicators did not explain the disparity in utilization of psychiatry services at $\mathrm{DF} / \mathrm{BCH}^{6}$. This suggests other utilization or suitability factors were at play. Such factors may include stereotypical beliefs, attitudes, or practices in the interactions between minorities and health providers that negatively influence clinical decision-making and effectiveness ${ }^{7}$. In this case such stereotypes may influence minority children's or parents' rapport with their oncology providers and willingness of parents to report mental or behavior symptoms, and oncologists' suspicion and threshold to make a psychiatric referral. Other practical social-cultural factors such as language barriers can influence utilization of services even when foreign language translators are used, particularly in the culturally sensitive realm of mental illness and behavioral disorders ${ }^{8}$.

Research to identify and quantify these disparities and their underlying mechanisms is critical to devise effective strategies that will overcome the systemic dynamics that deter minority children from accessing optimal cancer care. In the case of Zheng D.J. et al's findings, it would be very informative to determine the exact nature of the disparity by evaluating whether, (1) minorities were genuinely less likely to require a psychiatric consultation - a potential difference in disease epidemiology, (2) minorities needed psychiatric services but were not referred - suggesting inferior quality of care, (3) minorities were referred but never followed through on the psychiatric referral - a utilization problem. Mixed methods study designs that complement quantitative data with qualitative insights and involving key players (e.g., providers and minority patients in this case), can unveil critical issues around usability and acceptability that often underly underutilization of services.

Global and US disparities in pediatric cancer care and outcomes epitomize the public health adage that discovery of efficacious biomedical interventions does not automatically translate into improved health services and outcomes for those that need them. Whereas many pediatric oncology researchers are acutely aware of the difficulty to translate research innovations into bedside interventions ( $a k a$, "the valley of death") ${ }^{9}$, most children/families affected by cancer globally are on the wrong side of a pediatric oncology "death canyon" a complex milieu of financial, social-cultural, business interests, and health systems barriers that lie between them and the bedside (Figure 1). Enough scientific technologies have made it to the bedside to cure them, but only a few children can make it to the bed.

Research that bridges efficacious interventions and their delivery to children with cancer is critically needed. In addition to dedicateddisparities research, hybrid designs that build disparity questions in translational, clinical trials, and epidemiology research are likely to be efficient and even more informative. This requires broadening the scope of research teams and meticulous recruitment of appropriate socio-demographic strata of research participants. For global settings where the landscape of health systems infrastructure and organization and social-cultural norms are very different, implementation research is urgently needed to innovate strategies that will enhance the adoption of pediatric cancer best practices that suit the local context.

\section{References}

1. Zeng, C.; Wen, W.; Morgans, A. K.; Pao, W.; Shu, X. O.; Zheng, W., Disparities by Race, Age, and Sex in the Improvement of Survival for Major Cancers: Results From the National Cancer Institute Surveillance, 
Epidemiology, and End Results (SEER) Program in the United States, 1990 to 2010. JAMA Oncol 2015, 1 (1), 88-96.

2. Delavar, A.; Barnes, J. M.; Wang, X.; Johnson, K. J., Associations Between Race/Ethnicity and US Childhood and Adolescent Cancer Survival by Treatment Amenability. JAMA Pediatr 2020, 174 (5), 428436.

3. Atun, R.; Bhakta, N.; Denburg, A.; Frazier, A. L.; Friedrich, P.; Gupta, S.; Lam, C. G.; Ward, Z. J.; Yeh, J. M.; Allemani, C.; Coleman, M. P.; Di Carlo, V.; Loucaides, E.; Fitchett, E.; Girardi, F.; Horton, S. E.; Bray, F.; Steliarova-Foucher, E.; Sullivan, R.; Aitken, J. F.; Banavali, S.; Binagwaho, A.; Alcasabas, P.; Antillon, F.; Arora, R. S.; Barr, R. D.; Bouffet, E.; Challinor, J.; Fuentes-Alabi, S.; Gross, T.; Hagander, L.; Hoffman, R. I.; Herrera, C.; Kutluk, T.; Marcus, K. J.; Moreira, C.; Pritchard-Jones, K.; Ramirez, O.; Renner, L.; Robison, L. L.; Shalkow, J.; Sung, L.; Yeoh, A.; Rodriguez-Galindo, C., Sustainable care for children with cancer: a Lancet Oncology Commission.Lancet Oncol 2020, 21 (4), e185-e224.

4. Gramatges, M. M.; Deshpande, A.; Lupo, P. J.; Rau, R. E.; Redell, M. L.; Horton, T. M.; Scheurer, M. E.; Rabin, K. R., Ethnic disparities relative to disease features and outcomes in children with acute myeloid leukemia. Pediatr Blood Cancer 2017, 64 (9).

5. Gulliford, M.; Figueroa-Munoz, J.; Morgan, M.; Hughes, D.; Gibson, B.; Beech, R.; Hudson, M., What does 'access to health care' mean? J Health Serv Res Policy 2002, 7 (3), 186-8.

6. Zhao, J.; Han, X.; Zheng, Z.; Nogueira, L. M.; Nathan, P. C.; Lu, A.; Yabroff, K. R., Racial/ethnic disparities in childhood cancer survival in the United States: Mediation effects of health insurance coverage and area-level social deprivation. Journal of Clinical Oncology 2019,37 (27_suppl), 143-143.

7. Paradies, Y.; Truong, M.; Priest, N., A systematic review of the extent and measurement of healthcare provider racism. J Gen Intern Med 2014, 29 (2), 364-87.

8. Flores, G., Devising, implementing, and evaluating interventions to eliminate health care disparities in minority children.Pediatrics 2009, 124 Suppl 3 (Suppl 3), S214-23.

9. Butler, D., Translational research: Crossing the valley of death. Nature 2008, 453 (7197), 840-842.

\section{Legends}

Figure 1 Minorities and children with cancer globally face enormous challenges to access already proven pediatric cancer interventions (Illustration credit: Maria Mbasooka) 


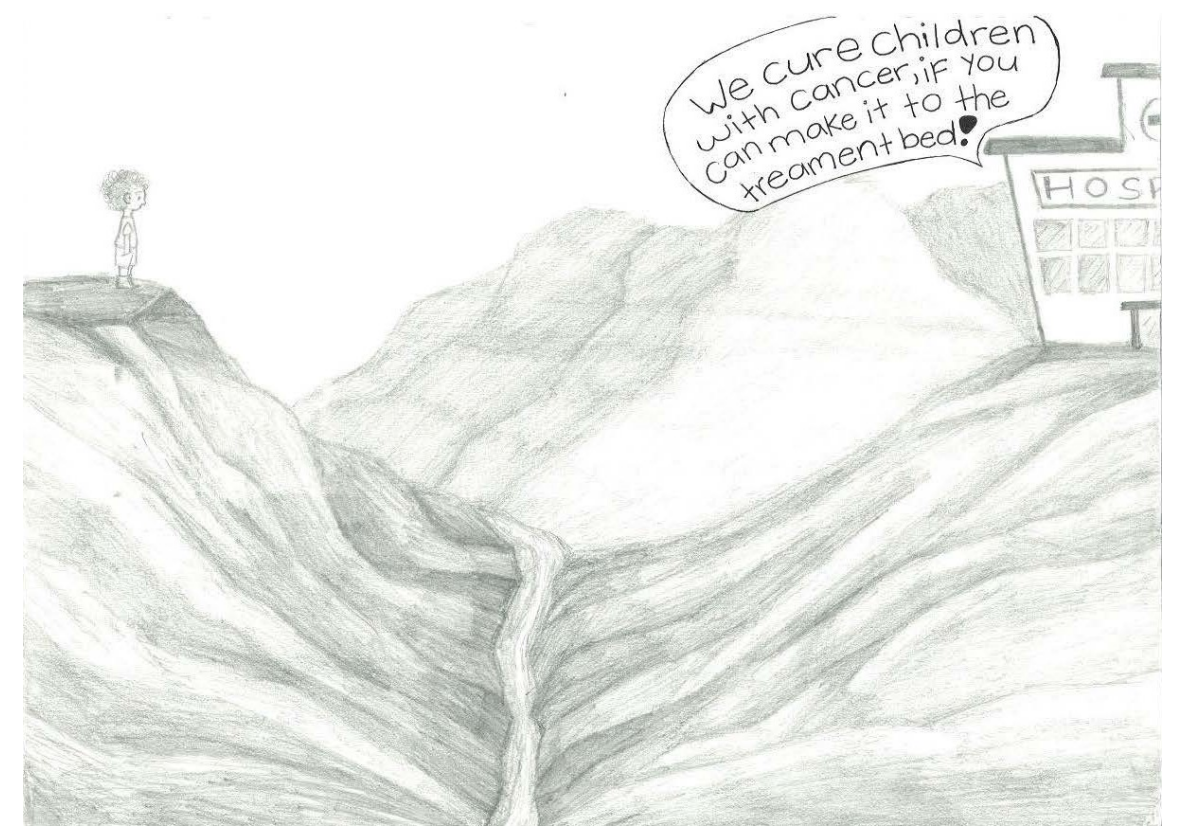

